\title{
Improving Bundled Inventory Flow for Services through Organizational Citizenship Behavior
}

\author{
John M. Woosley, Rachelle F. Cope, Robert F. Cope III, and David C. Wyld
}

\section{ABSTRACT}

\begin{abstract}
In our work, we hypothesize performance improvements to supply chain service operations through Organizational Citizenship Behavior (OCB). OCB is a term relating to voluntary actions of employees to help fellow employees and/or their organization through efforts that are not part of a contractual obligation. A key feature of OCB is that it is not rewarded in a formal manner. Through the years, OCB has gained substantial interest and has been studied across many organizational domains. In particular, we explore the roles of job cross-training and culture change in fostering OCBs that benefit the efficient operation of bundled inventories within the service firm.
\end{abstract}

Keywords: efficiency, inventory, organizational citizenship, organizational citizenship behavior, organizational culture, management, services, supply chain management, training.

\author{
Submitted : September 23, 2021 \\ Published : October 16, 2021 \\ ISSN: $2507-1076$ \\ DOI: $10.24018 /$ ejbmr.2021.6.5.1121 \\ John M. Woosley \\ Southeastern Louisiana University, \\ Hammond, LA, USA. \\ (e-mail: John.Woosley@southeastern.edu) \\ Rachelle F. Cope \\ Southeastern Louisiana University, \\ Hammond, LA, USA. \\ (e-mail: Rachelle.Cope $@$ southeastern.edu) \\ Robert F. Cope \\ Southeastern Louisiana University, \\ Hammond, LA, USA. \\ (e-mail: Robert.Cope ${ }^{\circledR}$ southeastern.edu) \\ David C. Wyld* \\ Southeastern Louisiana University, \\ Hammond, LA, USA. \\ (e-mail: david.wyld@ southeastern.edu) \\ *Corresponding Author
}

\section{INTRODUCTION}

Most supply chain service operations rely heavily on highly skilled labor/talent at the retail end of the chain. Interviews have shown that such highly skilled employees are generally attached to the methods, processes, brands, and products from their training. With significant diversity across these highly skilled professionals, supply chain inefficiencies come into play - overstocking of similar products, slow moving SKU's (stock keeping units), stockouts, obsolete process support, etc. While some diversity among a firm's service labor/talent is desirable, it may come at a cost of hindering efficient supply chain service operations. We explore Organizational Citizenship Behavior (OCB) to address some of the issues in service operations between the highly skilled professionals and the efficient operation of the firm's bundled inventory.

\section{TRAditional VS. SERVICES SuPPly CHAIN}

Some look at a traditional supply chain model of Fig. 1 [1] and question whether it adequately characterizes and captures operations in the services industry. In the traditional supply chain model, raw materials are converted to tangible goods and stored midstream and downstream to meet customer demand. Inventories are the main concern in such a system - raw material inventories, work-in-process inventories, and finished goods inventories - generally meeting independent demand, and are handled by inventory specialists using modeling techniques such as EOQ (Economic Order Quantity) and ABC Analysis [2].

However, it can be argued that the traditional supply chain model of Fig. 1 can indeed be used to characterize the services industry. In it, the emphasis on inventories meeting independent demand is replaced by the service rendered to the customer at the end of the chain. Inventories that support those services are consumed in smaller, but no less important numbers and are usually part of a bundle of service attributes which are dependent on the service requested.

\section{SERVICES AND THEIR BUNDLED RESOURCES}

In the services industry, output is often intangible and supported by dependent inventories through the supply chain. Many such services are nonstandard and vary greatly from customer to customer making pricing options more elaborate. There are several characteristics of services that illustrate their differences from traditional independent demand items, including:

- Usually not inventoried, they are consumed during/after production;

- High customer contact; 


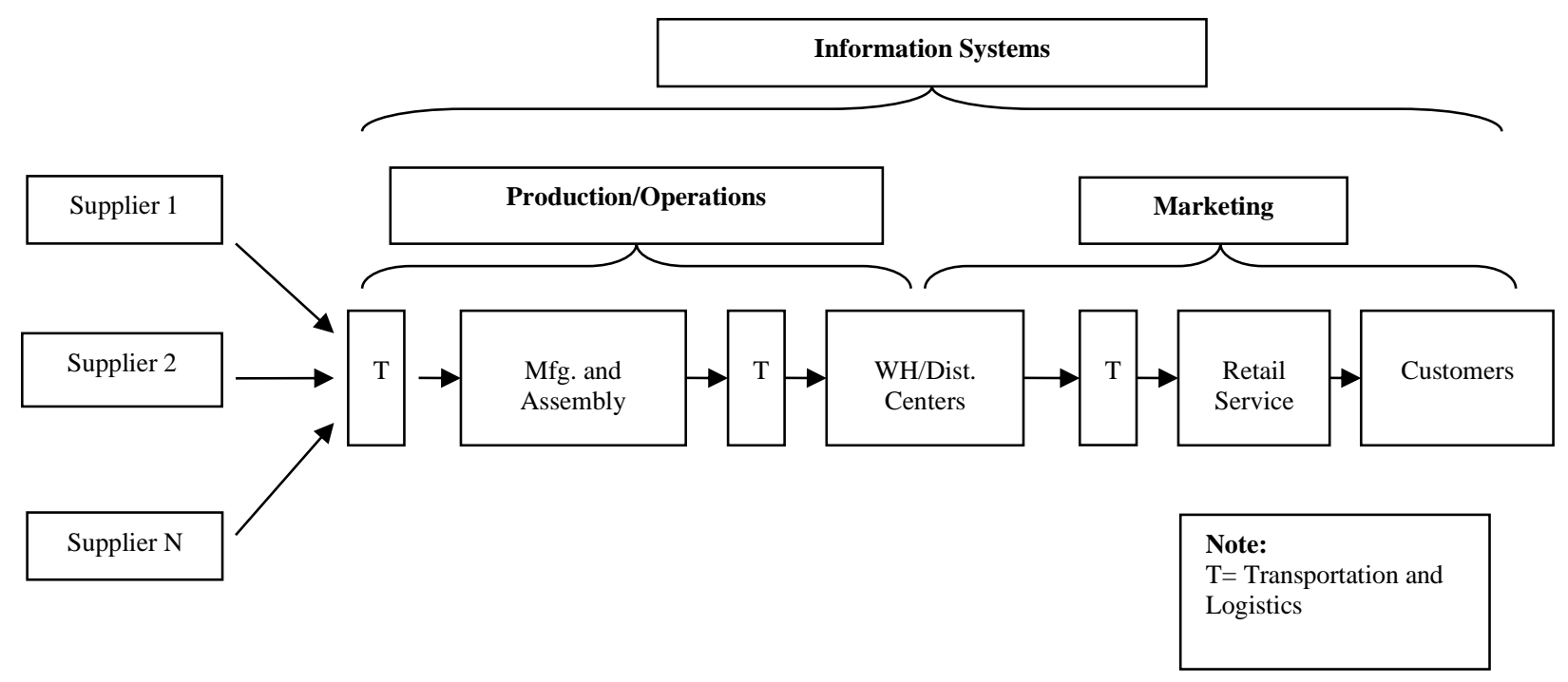

Fig. 1. Supply chain model.

- Customer participates in service;

- Personal skills/talent sold directly to the customer;

- Cannot be mass-produced;

- High personal judgment employed by those performing service;

- Labor intensive;

- Facilities located near customers;

- Measures of effectiveness are subjective;

- Quality control is limited to process control [3].

Additionally, services can be broken down into two types. First, there is "Front-of-the-House" service that can be described by the hiring of front-line service providers, or talent, that come face-to-face with the customer. They generally have good public relations skills and are given the power and resources to solve customer's problems quickly and effectively. As an example, think about the hair care or salon industry (many different brands). Then there is "Backof-the-House" service where customer interaction is not required, but the same level of power, technical skills and resource bundles are needed to complete the customer's request [4]. As an example, think about having your cell phone repaired (several brands using different component parts). Retail service delivery systems fall along a continuum of mass-produced, low-customer contact systems at one extreme (Back-of-the-House) and highly customized, highcustomer contact systems at the other (Front-of-the-House).

Supporting inventories are generally paired, or bundled, with what services are rendered. Thus, when a service is requested by a customer, a group of supporting items are generally called out for the specific service. Service bundles are generally broken down into several types found in Table I [4].

TABLE I: MAKE-UP OF BUNDLED INVENTORY FOR SERVICES

\begin{tabular}{ll}
\hline Explicit Service Component & $\begin{array}{l}\text { Primary inventory requirement for } \\
\text { customer service } \\
\text { Site, location specific inventory to } \\
\text { support service } \\
\text { Supporting Facility Component } \\
\text { Facilitating Goods Component }\end{array}$ \\
complete service \\
Implicit Services Component & $\begin{array}{l}\text { Secondary inventory requirements } \\
\text { of service provider }\end{array}$ \\
\hline
\end{tabular}

Both Front-of-the-House and Back-of-the-House services use similar bundle types. The problems that arise stem from dependent demand service bundles required by service talent vs. the independent demand operations of supply chain professionals, and the lack of communication between them.

\section{INEFFICIENCIES IN BUNDLED INVENTORY}

The service talent and customer make up the demand side of the problem. It has been postulated that there is indeed no such thing as a homogeneous market where all customers desire the same services presented in the same way [5]. Thus, different customers have different needs and requirements, and products and services only become meaningful when available and positioned from the customer's perspective. As for most services, sales volume is usually considered secondary to profit, and if variety is considered the spice of life, many kinds of inventory bundles are required for service.

Data was collected after visually inspecting warehouse inventory operations that supply resources to service operations. It was noted that inventory specialists were continuing in their usual manner of tracking and ordering items as if they were all required through independent demand. Not understanding the relationships of inventory items made for an inefficient use of capital, used up more warehouse space, and created fewer transactional opportunities.

Additionally, some of the more expensive service inventories were slow moving with poor turnover metrics and cash-to-cash conversion. Finally, it was noted that the slowest moving independent inventory items were transitioning to obsolescence with no value, becoming wasted capital, all because of a poor understanding of independent demand vs. dependent bundled demand for service support.

The important issue at hand turns out to be finding a mechanism for getting highly skilled service labor talent involved with the bundled inventory process or getting warehouse personnel involved in the highly skilled service process. Poor communication between the two groups was widely noticed. In an effort to integrate the two operations, we offer Organizational Citizenship Behavior. 


\section{ORgANiZATIONAL CITIZENSHIP BEHAVIOR (OCB)}

The phrase "Organizational Citizenship Behavior" (OCB) was first used in the 1980 s to denote organizationally beneficial behavior of workers that is not prescribed but occurs freely to help others achieve the task at hand [6]. OCB emphasizes the social context of the work environment in addition to the technical nature of the job. OCB has been defined in terms of pro-social behavior, altruism, and service orientation. Usually, these behaviors are not monitored by the organization's reward system but provide the organization with a long-term social advantage. It is true that what is considered OCB in one organization may not be considered OCB in another; for this reason, research has been conducted to assess OCB in many different organizational settings. The fact that the bundled resources to service providers require actions that cannot adequately be prescribed in a job description makes OCB an important aspect in retail service environments [7]. It should also be noted that OCBs do have the potential to take time from formal job roles to the extent that the main focus of the role is compromised. Consequently, it is important to ensure that $\mathrm{OCB}$, while a positive force, is not competing with intended work objectives [8].

\section{OBSERVED DIMENSIONS OF OCB}

Research conducted in order to define the dimensionality of OCB in organizations has provided conflicting results. The research has been grouped into two main themes for analyzing or promoting OCB. There appears to be support for a two-factor model to define OCB according to the beneficiary of the OCB with the following two factors:

1. OCB that benefits the organization in general, such as volunteering to serve on committees.

2. OCB that is directed primarily at individuals within the organization, such as altruism and interpersonal helping [9].

Correspondingly, defines the basic types of behavior that contribute to OCB are listed in Table II [10].

TABLE II: TYPES OF OCB EMPLOYEE BEHAVIOR

\begin{tabular}{ll}
\hline Altruism & Helping behaviors \\
Conscientiousness & Going beyond minimum role requirements \\
Civic Virtue & Deeply concerned about life of organization \\
Sportsmanship & $\begin{array}{l}\text { Willingness to tolerate less-than-ideal } \\
\text { organizational circumstances without } \\
\text { complaining (rolling with the punches) }\end{array}$ \\
& $\begin{array}{l}\text { Preventing work-related conflicts as well as } \\
\text { being polite and considerate }\end{array}$ \\
\hline
\end{tabular}

To apply these findings to work environments, understanding examples of the behavior characteristics of citizenship behaviors is a useful way to identify and encourage OCBs in employees [10]. First, individual employee's exhibited forms of OCB may stem from different motivations. For example, courtesy may be motivated by image management for one employee and by quality of work for another. Also, a single OCB may serve more than one motive, as in the case when conscientious employees work extra hours for contribution to excellence versus opportunity for promotion. Altruism may be displayed by individuals in accordance with personal goals in both long- and short-term dimensions. For example, an employee may drive a boss to work as an immediate helping gesture, but also realize the possible long-term benefit for this act of kindness. Civic virtue is achieved by giving new recruits tips on working with company resources. If an employee changes work shifts or covers for another co-worker, sportsmanship is present when the facilitating employee does so willfully.

As an extension of fundamental OCB theory, prior research [11] has shown the need to determine justification for OCB's ability to enhance organizational performance (in their study of work group performance), identify possible factors as one or more of the following:

- Reduce the need to devote scarce resources to purely maintenance functions

- Free resources for more productive purposes

- Enhance co-worker and managerial productivity

- Serve as a means of coordinating activities between team members and across groups

- Enhance the organization's ability to attract and retain the best people.

We can further our attention to the benefits of OCB by focusing on how it motivates different roles within services.

\section{OCB BENEFITS}

The benefits of OCB have been studied in various environments, and in particular studies have shown that OCB results in benefits for both individuals and organizations [12] . Considering the organizational benefits of OCB, there is an important distinction between Affiliative and Challenging OCBs [13]. Affiliative OCBs are those that support existing processes to maintain present circumstances. An organizational example of this would be giving new recruits tips on working with company resources. Comparatively, Challenging $\mathrm{OCBS}$ are directed at changing current circumstances by taking initiative. This would be the case if an organization searched for partners who could provide training.

Finally, employees may perform OCBs for the interest of their organization even if they, as individuals, are not directly rewarded. Consequently, employees' willingness to engage in OCBs is likely to be linked to their underlying views regarding the relationship between the individual and the group [14]. With this realization, organizations should embrace the study of OCB as a learning opportunity [15]. The degree to which OCBs are encouraged by a common purpose and strategic thinking will serve as an important benefit to organizations. Managers may benefit from paying special attention to relationships with workers. By showing more concern for employees' needs and responding to employees' requests for help, employees will be more likely to perceive supervisor support and feel they are truly valued in the workplace-resulting in more OCB that will benefit the organization [16].

\section{APPLICATION TO SUPPLY CHAIN FLOW FOR SERVICES}

We have seen how OCB can provide a mechanism for stronger relationships between service talent and operations personnel in the services industry. When inventory specialists 
are highly motivated by the success of the firm (also beneficial to the individual), the desire to display the five OCB characteristics is enhanced. This brings about a better understanding of the needs and responsibilities of everyone's jobs within the firm, which should lead to a higher level of understanding of the services offered by the firm and the bundled resources required for them.

To advance OCBs in the services industry, top-down support must be present for the culture changes necessary to promote the five OCB characteristics. Without support across all levels of management, OCB initiatives will not be viewed as a vital component of positive organizational culture. In addition to the inherent motivation for operational efficiencies for economic benefit, management needs to fully understand the impact of the OCB characteristics discussed. Altruism, conscientiousness, civic virtue, sportsmanship, and courtesy should not be viewed as trivial gestures, but the foundation of a culture with strategic priorities. Two possible strategies to foster OCB characteristics could include crosstraining, greater horizontal and vertical responsibilities, and stronger channels of communication.

\section{CONCLUSIONS AND DIRECTIONS FOR FURTHER RESEARCH}

Organizational Citizenship Behavior involves a variety of employee actions that are not included as part of their assigned roles but go beyond that which is expected. When these non-compulsory actions benefit the organization, OCB is a beneficial aspect of organizational culture. Our theoretical application described the foundations of OCB and observed the phenomenon in the setting of supply chain service activities. In particular, OCB characteristics and incentives between the service talent and operations personnel were considered.

Fundamentally, OCB is considered a positive force when it serves to increase overall organizational productivity. Thus, skilled service talent must be motivated to serve as role models with open lines of communication with all support personnel. Since productivity and quality metrics are recorded for all employees, the goal is to encourage all inventory specialists to work carefully with service talent to continually improve the efficiency of the firm. Improvements to variances in bundled resources might include, but are not limited to improved service speed, improved service quality, improved inventory procurement practices, and minimized inventory obsolescence and damage.

The purpose of this research was to investigate the need for complementary OCB effects within supply chain services. Through this study, the research can be extended to other areas of Supply Chain Management. Other manufacturing, warehouse, distribution, and even transportation operations are applicable. Additionally, areas of future research could include mechanisms for organizations to better understand the practices that are necessary to allow OCBs to emerge. These areas include defining characteristics and behaviors that are beneficial to the organization and the individual. OCBs can help an organization achieve higher levels of efficiency and a strategic advantage when a balance of these behaviors contributes to a positive and more productive work environment.

\section{REFERENCES}

[1] M. Jones, R. Cope, and M. Budden, "The multidisciplinary nature of supply chain management: Where does it fit in business education?" American Journal of Business Education, vol. 2, no. 1, pp. 17-24, Jan. 2009.

[2] W. Stevenson, Operations Management. 12th ed. New York, NY: McGraw-Hill, 2015.

[3] R. Murdick, B. Render, and R. Russell, Service Operations Management. Boston, MA: Allyn and Bacon, 1990.

[4] J. Wisner, K. Tan, and G. Leong, Principles of Supply Chain Management. 3rd ed. Mason, $\mathrm{OH}$ : South-Western Cengage Learning, 2009.

[5] D. Bowersox, D. Closs, M. Cooper, and J. Bowersox, Supply Chain Logistics Management. 4th ed. New York, NY: McGraw-Hill, 2013.

[6] C. Smith, D. Organ, and J. Near, "Organizational citizenship behavior: Its nature and antecedents.” Journal of Applied Psychology. vol. 68, pp. 655-663, 1983.

[7] M. DiPaola and W. Hoy, "School characteristics that foster organizational citizenship behavior." Journal of School Leadership, vol. 15 , no. 4 , pp. 387-406, 2005.

[8] H. Pickford and G. Joy, "Organizational citizenship behavior: Definitions and dimensions." Saïd Business School Research, MIB Briefing No.1, August 2016.

[9] L. Williams and S. Anderson, "Job satisfaction and organizational commitment as predictors of organizational citizenship and in-role behavior." Journal of Management, vol. 17, pp. 601-606, 1991.

[10] D. Organ, Organizational Citizenship Behavior: The Good Soldier Syndrome. Lexington, MA: Lexington Books, 1988.

[11] N. Podsakoff, P. Podsakoff, S. Whiting, and B. Blume, "Individualand organizational-level consequences of organizational citizenship behavior: A meta-analysis." Journal of Applied Psychology. vol. 94, no. 1, pp. 122-141, 2009.

[12] J. Halbesleben and T. Bellairs, "What are the motives for employees to exhibit citizenship behavior? A review of prosocial and instrumental predictors of organizational citizenship behavior." The Oxford Handbook of Organizational Citizenship Behavior (P. Podsakoff, N Podsakoff and S.. Mackenzie, eds.). Oxford, UK: Oxford Handbook Online (DOI: 10.1093/oxfordhb/9780190219000.001.0001), May 2019.

[13] A. Grant and D. Mayer, "Good soldiers and good actors: Prosocial and impression management motives as interactive predictors of affiliative citizenship behaviors." Journal of Applied Psychology, vol. 94, no. 4, pp. 900-912, 2009.

[14] R. Moorman and G. Blakely, "Individualism-collectivism as an individual difference predictor of organizational citizenship behavior." Journal of Organizational Behavior, vol. 16, no. 1, pp. 127-142, 1995

[15] A. Somech and A. Drach-Zahavy, "Exploring organizational citizenship behaviour from an organizational perspective: The relationship between organizational learning and organizationa citizenship behaviour." Journal of Occupational and Organizational Psychology, vol. 77, no. 3, pp. 281-298, 2004.

[16] L. Wang, K. Hinrichs, L. Prieto and Jon Howell, "Five dimensions of organizational citizenship behavior: Comparing antecedents and levels of engagement in China and the US," Asia Pacific Journal of Management, vol. 30, no. 1, pp. 115-147, 2013.

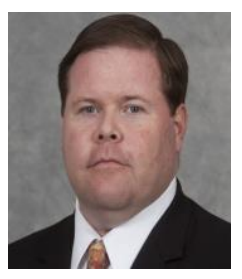

Dr. John M. Woosley was born in Memphis, Tennessee. He received a Ph.D. in Business Administration with a concentration in Information Systems and Decision Sciences from Louisiana State University in Baton Rouge, Louisiana in 2009. His major field of study was Information Systems and Decision Sciences (ISDS). He also received an MS in ISDS (2003), an MS in Kinesiology with a specialization in motor behavior (2000), and a Bachelor of Science degree in Kinesiology (1997) from Louisiana State University in Baton Rouge.

$\mathrm{He}$ is an Associate Professor of Supply Chain Management at Southeastern Louisiana University in Hammond, Louisiana. Before joining the faculty at Southeastern Louisiana University, he was a Database Administrator with the Louisiana Recovery Corp. and was an Assistant Coach with Louisiana State University Track and Field. He teaches courses in Production and Operations Management, Principles of Supply Chain Management, and Management Information Systems. His research interests include pharmaceutical inventory control, sustainability, medical information quality assurance, and logistics and transportation optimization.

Dr. Woosley has been or is currently a member of several academic societies like DSI, AIS, and ABR and has served as a reviewer for numerous journals in his field. He continues to serve his university and his academic 
societies/conferences in many capacities. In addition, he has received best paper awards for conference presentations.

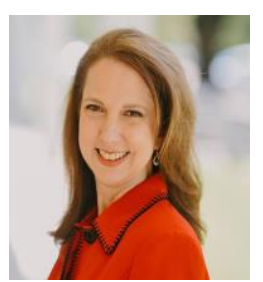

Dr. Rachelle F. Cope was born and raised in south Louisiana along Bayou Lafourche near Thibodaux, Louisiana. She received a Ph.D. in Business Administration with a concentration in Information Systems and Decision Sciences from Louisiana State University in Baton Rouge, Louisiana in 1996. Her major field of study was Information Systems with a minor in Operations Research. She received her undergraduate degree from Nicholls State University in Thibodaux, Louisiana in 1987 with majors in Computer Science and Mathematics. Before entering the Ph.D. program at LSU, Dr. Cope gained experience as a Programmer/Analyst at Pan American Life Insurance Company in New Orleans, Louisiana in the Group Actuarial Division.

Currently, she is a Professor of Operations Management and Information Systems at Southeastern Louisiana University in Hammond, Louisiana and has been part of their faculty since 1993. She teaches courses in Principles of Supply Chain Management, Information Systems, Database Management, Business Analytics, and Statistics. She has published over 40 articles in refereed journals and proceedings and has made numerous academic presentations throughout her career. Her research interests include applications of knowledge management, behavioral aspects of information systems and supply chain management environments, resource optimization techniques, statistical modeling, and implications of supply chain legislation.

Dr. Rachelle Cope is a lifetime member of the Honor Society of Phi Kappa Phi and is currently a member of the INFORMS professional society. She spent fifteen years as the College of Business Team Captain for the American Cancer Society's Relay for Life event at Southeastern. She is currently the recipient of a Dorcas and H. N. Capron, Jr. Endowed Professorship in Supply Chain Management at Southeastern.

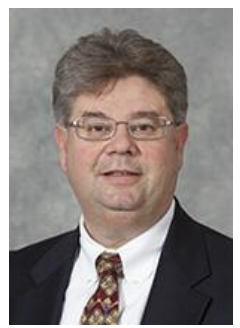

Dr. Robert F. Cope III was born in New Orleans, Louisiana. He received a Ph.D. in Business Administration with a concentration in Information Systems and Decision Sciences from Louisiana State University in Baton Rouge, Louisiana in 1998. His major field of study was Operations Management while his minor field was Industrial Engineering. He also received an MBA (1991) and a Bachelor of Science degree in Electrical Engineering with an Energy specialization (1986) from Louisiana State University in Baton Rouge.

He is a Professor of Operations Management at Southeastern Louisiana University in Hammond, Louisiana. Before entering academia, he was a Field Services Engineer with GE and an Underground Zone Technical Engineer with Houston Lighting \& Power Company. He currently teaches courses in Management Science, Project Management, Principles of Supply Chain Management, Production and Operations Management, and Logistics Management \& Transportation. He has published over 45 articles and has made numerous professional and academic presentations throughout his career. His research interests include resource optimization techniques, scheduling, energy modeling, project management, statistical modeling, and the design of information technology.

Dr. Cope is currently a member of the USAEE/IAEE, INFORMS, and IEEE academic and professional societies, and has served as a reviewer for several journals in his field. He is currently the recipient of the Dorcas and H. N. Capron, Jr. Endowed Professorship in Supply Chain Management at Southeastern, and is a registered Professional Electrical Engineer with the states of Louisiana and Texas.

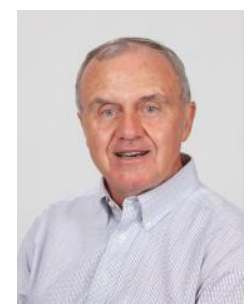

Dr. David C. Wyld was born and raised in the Dallas, Texas area. He received a D.B.A. in Management from the University of Memphis in 1993. Previously, he had earned both an M.B.A. and a B.B.A. from Stephen F. Austin State University in Nacogdoches, Texas in 1985 and 1984, respectively.

$\mathrm{He}$ currently serves as the Merritt Professor of Strategic Management at Southeastern Louisiana University in Hammond, Louisiana. Dr. Wyld is the founder and publisher of both Modern Business Press (publishing leading-edge academic journals) and The IDEA Publishing (publishing articles of interest across a wide variety of topics, giving both newbie authors and content marketers a platform for their ideas). As a prolific writer himself, he is a frequent contributor to both respected academic journals and widely read trade and general interest publications. He has established himself as one of the leading academic experts on emerging applications of technology in both the private and public sectors. Dr. Wyld continues to be an active strategic management consultant, a qualified expert witness, and invited speaker on a wide variety of topics to trade, corporate, governmental, and academic audiences.

Dr. Wyld has earned Southeastern's President's Award for both Excellence in Teaching and Research, making him one of a select group of faculty who have been awarded campus-wide recognition for more than one aspect of the professorial role. 